\title{
Challenges of Improving the Quality of Academic Supervision of Postgraduate Studies at the Faculty of Education, Damietta University
}

\author{
Aly Saleh Gohar (Corresponding author) \\ Professor of Educational Planning, Faculty of Education \\ Damietta University, Damietta, Egypt \\ Marwa Maher Qouta \\ Lecturer in Fundamentals of Education, Faculty of Education \\ Damietta University, Damietta, Egypt
}

Received: February 6, 2021

Accepted: March 1, 2021 Published: March 21, 2021

doi:10.5296/jei.v7i1.18292

URL: https://doi.org/10.5296/jei.v7i1.18292

\begin{abstract}
The present research paper aims to confront the challenges of improving the quality of academic supervision of postgraduate studies at the Faculty of Education, Damietta University, identifying the theoretical and conceptual framework for academic supervision of educational postgraduate studies. It also analyzes the reality and defines the challenges of academic supervision of educational postgraduate studies. The author adopted the descriptive and analytical method and applied the tool to a sample of (30) faculty members at the Faculty of Education, Damietta University. The study concluded that the heavy load of the supervisor, the tendency of the student to choose a supervisor in a certain position, and keenness of the student to carry out the study quickly without considering quality, and poor research skills among students are the most significant challenges of improving the quality of academic supervision. The study recommended abiding by the regulations of postgraduate studies that allow supervising several theses and dissertations to enable supervisors to follow up postgraduate students honestly and objectively. It also recommended the need to respect the desire of the student when choosing a supervisor.
\end{abstract}

Keywords: Academic supervision, Postgraduate studies, Faculty of Education, Educational studies 


\section{Introduction}

Educational research is an important field because it aims at the optimal form of educating the individual by developing the educational practices to ensure acquiring, producing, and employing knowledge. It helps promote educational methods, make and define the educational policy, support relevant educational decisions, and access new educational knowledge that meets the requirements of continuous educational innovation.

Educational research is one of the outcomes provided by the university to the society to help resolve problems and develop current status at all levels. Therefore, the role of scientific production is not measured by the number of studies, but how they contribute to changing current status by employing their results to develop a certain field within an integrated system (Marzuq, 2017).

Postgraduate studies are one of the most significant university programs that mainly focus on exploring and developing different capacities of society. They help develop science to drive social development (Alloma, 2019). Currently, one of the important issues is the key role of educational postgraduate studies in developing and employing educational studies as a key concern of the colleges of education. Moreover, postgraduate studies at the colleges of education have responsibilities and functions imposed by contemporary challenges in education.

A faculty member is a major pillar of university education and an active part of development because of the key role played in delivering information and knowledge to students. Therefore, the competence of a faculty member is not measured by one's knowledge in the field, such as facts, concepts, and theories only, but teaching competence, continuing research, supervision, guidance, and community service play a considerable role (Alnaqa, 2005).

Academic supervision of the faculty member is one of the important roles because a researcher needs a supervisor to promote one's research skills to integrate academic supervision based on both roles (Ali \& Merghany, 2011).

Therefore, the author has been motivated to conduct the present study to identify and resolve the most important challenges facing academic supervision.

\subsection{Statement of the Problem}

To confront the challenges of the rapid change of economic and social life aspects and the flow of knowledge as a result of scientific progress and its technological applications, developing and promoting postgraduate studies has become a highly important issue. Postgraduate studies provide the society with educational and technical cadres for comprehensive and substantial development. They have received considerable interest in the different societies as an indicator of progress and community development, on one hand, and a means to promote the academic reputation of universities to promote their academic studies, on the other.

Academic supervision plays an active role in promoting educational research. Several 
universities worldwide have paid attention to the role of the faculty members as academic supervisors by holding training programs, conferences, and seminars. Moreover, some universities have established the supervision of a faculty member on postgraduate students as a requirement for joining these programs (Al-Tokhi, 2011). Despite the importance of academic supervision, Johansen, Olsen, Øverby, Garred, and Enoksen (2019) reported an imbalance of power in supervision teams and that the main part of supervision is the responsibility of the primary supervisor.

Academic supervision of postgraduate studies suffers several problems. According to Assakran (2016), there are many obstacles to the role of the academic supervisor, such as heavy load, lack of experience, and lack of commitment to the office hours. El-Deeb (2016) highlighted some obstacles, such as lack of full-time supervision due to heavy academic and teaching duties, as well as participation in conferences and scientific committees. Moreover, Abulsaoud (2020) argued that many obstacles hinder educational research, such as lack of incentives and heavy teaching and administrative loads among supervisors.

The problem of the present study is defined in asking the following major question:

What are the challenges of improving the quality of academic supervision of educational postgraduate studies at Damietta University?

It is divided into the following minor questions:

(1) What is the reality of academic supervision of educational postgraduate studies?

(2) What are the most important global models of academic supervision?

(3) What are the obstacles to academic supervision of educational postgraduate studies?

\subsection{Objectives}

The study mainly aims to resolve the challenges of improving the quality of academic supervision of educational postgraduate studies at Damietta University.

It could be achieved by:

(1) Analyzing the reality of academic supervision of educational postgraduate studies.

(2) Identifying the most important global models of academic supervision.

(3) Defining the obstacles to academic supervision of educational postgraduate studies.

\subsection{Significance}

(1) It is a significant study because of its important topic, i.e., academic supervision of educational postgraduate studies.

(2) It aims to promote, enhance, and employ educational postgraduate studies.

(3) It is interested in faculty members as a basic pillar of university education and its development. 
(4) It helps improve academic supervision of educational postgraduate studies and monitoring postgraduate students.

\subsection{Method}

The study adopted the analytical descriptive method that describes, analyzes, and discusses the phenomenon.

\subsection{Limits}

The study was limited to the following:

$\checkmark$ Topic limits: Challenges of improving the quality of academic supervision of educational postgraduate studies at Damietta University;

$\checkmark$ Human limits: Faculty members at Damietta University;

$\checkmark$ Spatial limits: Faculty of Education, Damietta University;

$\checkmark$ Temporal limits: 2020-2021.

\subsection{Definition of Terms}

\subsubsection{Quality}

Quality means providing good speaking and deeds. Terminologically, quality of education is the wet of efforts made by officials to develop the educational outcome (student- class- stage) to match the requirements of society. It also indicates the ability of educational departments to fulfill their tasks to produce a graduate with certain specifications to meet the needs of social development (Falia \& Alzaky, 2004).

\subsubsection{Academic Supervision}

It is the interaction between a faculty member and postgraduate students. It is an organized operation with rules, basics, and regulations to define and control this interaction. Moreover, it is multifaceted and includes academic, administrative, and human aspects. It is one of the tasks of a faculty member Assakran (2016).

\subsubsection{Educational Postgraduate Studies}

This stage follows the undergraduate stage where studies pursue studies to obtain academic degrees, e.g., diploma, master, and doctorate at an educational department supervised by specialized professors according to a certain method of selection, preparation, as well as the academic and professional qualification (Madkour, 2000).

\subsection{Theoretical Framework}

\subsubsection{Objectives of the Educational Postgraduate Studies}

Postgraduate studies can fulfill the desired outcomes with good planning and clear objectives. According to Ibrahim (2017), educational postgraduate studies aim to: 
$\checkmark$ Enrich and promote human knowledge through research, exploration, openness, and objective study of intellectual and cultural heritage.

$\checkmark \quad$ Provide researchers with scientific research skills, e.g., defining the problem, making and testing hypotheses, preparing tools, as well as collecting and discussing data.

$\checkmark$ Enrich the knowledge of postgraduate students to meet the current and anticipated needs and develop them professionally.

$\checkmark$ Respond to social needs and development requirements by making and following up these plans, providing scientific consultations to production centers, and guide research to handle various development issues.

$\checkmark$ Resolve the problems caused by the scientific and technological revolution in a scientific comprehensive manner and carry out applied studies to link the university to society.

In short, objectives correlate concerning the cognitive, social, and economic aspects. The success of achieving the university mission is measured by the effective roles, outcome size, self-development, communication with the society, addressing societal problems, and developing modern methods to resolve obstacles.

\subsubsection{Concept of Academic Supervision}

Despite its several definitions, academic supervision general means the guidance of the students of master's and doctoral degrees by faculty members commissioned by the department. It ends with the preparation and examination of the dissertation or theses (Abu Daf, 2002). According to Mustafa (2004), it is a technical process by a faculty member or more based on their expertise and competencies to guide, monitor, and support a researcher in a relevant study to obtain an academic degree.

Noureddine (2009) defines it as the guidance of a researcher by a specialized professor concerning studying and discussing a topic and concluding results according to defined academic standards. Academic supervision is a set of academic practices to study an issue to highlight certain facts by a researcher supervised by a specialist (supervisor) (Hassan, 2010).

Al-Tokhi (2011) reports that academic supervision has the following two main features:

$\checkmark$ It is a humanitarian interactive process: It is a human interaction between the supervisor and researcher, resulting in several relationships and expectations. Power relationships are the most common because the supervisor is the expert, whereas the researcher is a follower. Thus, supervisors should consider the opinions of students and encourage them. The supervisor-researcher relationship should rely on trust, respect, and appreciation.

Moreover, several conflicts are caused by the conflicting expectations between the supervisor and researcher. 
$\checkmark \quad$ It is a difficult and complex process: Many factors affect supervision, especially in this evolving age with many changes and challenges imposed by globalization, knowledge revolution, and economy that deeply affect the quality of education and research at universities.

Academic supervision is important because:

$\checkmark$ It motivates students to identify their strengths and weaknesses and to use their knowledge to enrich the learning process in research. It also enhances their opportunity to identify the skills, knowledge, and competencies they have and promote selfconfidence (Down, Martin, \& Bricknell, 2000).

It is one of the most important factors that affect student progress in research. It represents the most important source of support and guidance in terms of research, academic, social, psychological, and administrative aspects (Shaban, 2017).

$\checkmark$ The supervisor increases the supervisor's experience and ability to find different ways to resolve the problems of students (Assaf, 2014).

\subsubsection{Objectives of Academic Supervision}

Calma (2008) argues that supervision primarily aims to ensure that the researcher has the necessary traits and skills to conduct research based on acceptable scientific standards and the researcher receives the necessary support and assistance to complete the thesis or dissertation.

Shaban (2017) defines the objectives of supervision, as follows:

(1) Directing the researcher to carry out the task of scientific research based on the guidance to the right path and resolving difficulties.

(2) Teaching the researcher the proper method of achievement and providing experiences, knowledge, and skills necessary.

(3) Evaluating the researcher's ideas and highlighting talents.

(4) Taking care of building the personality of the researcher.

1.7.4 The Role of the Supervisor

Supervision is a very important and complex role. The quality of supervision promotes the quality of research, which is a basic function of the university. According to Assaf (2014) and Assakran (2016), supervisors play many significant roles.

There are also many roles that the academic supervisor plays to assist:

$\checkmark \quad$ The supervisor as a director: The supervisor directs the researcher in defining a field, choosing the appropriate method, identifying objectives, and supervising the preparation of the proposal.

$\checkmark$ The supervisor as a teacher: The supervisor teaches the students by providing them with research skills. 
$\checkmark \quad$ The supervisor as a mentor: The supervisor helps the student resolve the problems in research and guides him/her to the scientific method in resolving problems, identifying suitable alternatives, and linking means and goals.

$\checkmark \quad$ The supervisor as a planner: The supervisor suggests a timeline for the completion of the research according to specific stages and provides the student with feedback.

$\checkmark$ The humanitarian and ethical role: The supervisor is interested in the personal aspects of the researcher, discusses ideas of interest, and motivates him/her.

$\checkmark$ The administrative roles: The supervisor provides the student with basic directions and administrative procedures that must be considered while enrollment and completion of the study.

$\checkmark$ The supervisor as a mentor: The supervisor monitors the researcher's progress and commitment to implementing duties and responsibilities.

The supervisor as an evaluator: Evaluation is one of the important roles of the supervisor.

$\checkmark$ The supervisor as a facilitator: The supervisor facilitates the student's scientific research process, provides indicators to organize the work, and resolve the academic, administrative, or social challenges.

According to Diab (2009), supervision requires that the supervisor should have some features:

(1) Scientific competence: The supervisor should master the skills of planning, organization, coordination, direction, and follow-up and develop research and supervision capabilities by reviewing the latest updates in the field.

(2) Moral distinction: The supervisor has morals, including sincerity, cooperation, humility, and patience.

(3) Sincerity: The supervisor should work purely for the sake of Allah and appreciate the need of students for instruction and guidance.

(4) Communication and interaction with others: The supervisor should master communication skills with students and colleagues.

(5) A good example: The supervisor should set a good example for the supervised students.

(6) Devotion to supervision: The supervision process needs great effort and adequate time. It is difficult for any supervisor to assume a large teaching load because this reflects negatively on the supervision performance.

The difficulty of supervision appears in the direct responsibility of the supervisor for the researcher. It is easier for a faculty member to conduct research to enrich the teaching process or to fulfill the requirements of the university for the sake of promotion. However, 
supervision is a greater responsibility because a supervisor is the first responsible for the student. This supervisory relationship includes many obligations on the part of the faculty member towards the student from dedicating time and advising to defense (Al-Sawi, 2006).

Al-Tokhi (2011) argues that the role of the supervisor takes many dimensions, such as:

(1) The supervisor as a researcher: Supervision is primarily related to scientific research, and the supervisor is a specialized researcher. Consequently, a researcher must have broad and good knowledge in the field of research or must have some experience in conducting related research at least. The research activity and interest of the supervisor in the research subject are necessary for effective supervision.

This role requires the supervisor to be familiar with the latest studies, research, and trends in the field, to re-establish the field of work in terms of choosing students and directing them to choose topics of a new nature, and to make sure, based on experience, that the student has the research skills to do the research. The supervisor must continuously develop his/her research skills by being aware of new developments in the field in terms of modern methods, techniques, and means of collecting data, generating knowledge, and using technology in research. The supervisor must also participate in conferences, societies, and scientific periodicals and motivate students to do so.

(2) The supervisor as a mentor and counselor: Guidance and counseling are the central part of the research supervision process. Despite changing the methods and practices of research supervision over the years, the main unchanging feature of supervisors is that they direct students to the organized method for discovering knowledge.

(3) The supervisor as a teacher: The supervisor is primarily a teacher. Many researchers take their professors as a model. The supervisor should promote the ethics of scientific research among students, e.g., honesty, modesty, objectivity, justice, fairness, intellectual flexibility, appreciation of the efforts of others, as well as the commitment to the common values, morals, beliefs, and heritage.

(4) The supervisor as a practitioner: This role is intended to reflect on the supervisor's work and role as a supervisor, ideas, practices, and continuous evaluation to improve such ideas and increase knowledge and skills. Supervisors should work on two basic aspects. First, the supervisor should be aware of the nature, objectives, and factors of supervision. Second, the supervisor should know what to do as a practitioner and achieve a balance between the different roles to be played.

Reviewing the regulation of postgraduate studies at Damietta University shows regulating articles of academic supervision (i.e., Articles 6, 7, and 10). There are also regulating articles in the regulation of the faculty (i.e., 30-42).

Articles regulating academic supervision in the regulation of postgraduate studies at Damietta University:

Article (6): Identification of the supervisor(s): 
(1) Based on the proposal of the relevant department council, the faculty council appoints a professor to supervise the preparation of the thesis/dissertation. The council may entrust this supervision to one assistant professor or several supervisors of the faculty members or other experienced supervisors. Lecturers may participate in supervision.

(2) If the student conducts some experiments outside the university, it is permissible, upon a proposal from the faculty board and upon the approval of the council of postgraduate studies and research, to allow a specialist from the affiliation in which experiments are conducted to participate in supervising.

(3) Lecturers may participate in supervising the thesis with a maximum of one lecturer for each relevant specialization. A supervising lecturer should submit a published or accepted for publication paper in a refereed journal or a book of a specialized conference conducted after appointment to the position of lecturer.

(4) Several faculty members could be supervisors with a maximum number of three for the master's thesis and four for the doctoral dissertation. In the case of co-supervision, the foreign supervisor is counted among the four.

(5) If a foreign supervisor is added to the committee of supervising a doctoral dissertation who are not holders of joint supervision missions, he/she is treated financially as a visiting professor if he/she is recruited, provided that this is from the research fund- the faculty share.

(6) A professor could not supervise or participate in supervising more than twenty theses and dissertations at the same time. An assistant professor should not exceed the number of fifteen, whereas a teacher should not supervise more than twelve. These numbers increase by twenty at most about foreign students, for all the faculty members.

(7) It is not permissible for the members of the supervising committee to relate to the student by kinship or lineage up to the fourth degree or any kind of disagreement. A signed declaration from the supervisor, the head of the department, and the dean is acceptable. The committee shall immediately amend it once a contradicting issue raises.

(8) The name of the deceased supervisor may remain on the thesis or dissertation if more than half of the period has passed since registration in the faculty regulation.

Article (7): Modification of the supervision committee

(1) A member of the supervision committee may omit his/her name from the committee at his request, provided that one of the professors or assistant professors remains. It is also permissible to add one of the specialists from the faculty members or others to the supervision committee with his/her approval and based on the suggestion of the supervisors with an explanation of the reason for the addition. In this case, the thesis/dissertation is not examined before six months from the date of addition. 
(2) The modification of the supervision committee shall be based on the suggestion of the department and faculty councils with the approval of the university postgraduate studies council.

(3) The faculty council may, based on the department council's suggestion and in exceptional and justified circumstances, add or remove a member from the supervision committee, with no violation of the general requirements of registration.

Article (10): Periodic reports

(1) The number of postgraduate students' meetings with supervisors shall be at least four per year.

(2) The principal supervisor submits a report to follow up the attendance and response of the student every three months approved by the head of the department. Furthermore, the supervisors submit an annual report on the progress of the student approved by the department council, the postgraduate studies committee, and the faculty council, and the university general department of postgraduate studies. All the reports are regular, complete, and approved.

(3) The annual report includes the title of the thesis/dissertation in both Arabic and foreign languages.

(4) There must be an annual development in the average reports. Otherwise, this is considered a lack of progress in the study that requires consideration of canceling the registration.

(5) The student shall be notified of the content of the completed and approved report. $\mathrm{He} /$ she shall sign the report.

(6) If the supervisor or one of the supervisors is seconded or fully delegated outside the university, a report is presented to the faculty council on the achievement of the student. Accordingly, the council appoints a supervisor to the supervision committee if necessary if half of the stated period has not passed.

\subsubsection{The Most Significant International Models of Academic Supervision}

Australia (McCulloch, Kumar, Van Schalkwyk, \& Wisker, 2016)

In 2017, the Australian Council of Graduate Research (formerly the Australian Graduate Board of Deans and Directors of Graduate Studies) issued the first framework of postgraduate studied that was revised and replaced by the Graduate Research Good Practice Principles in 2010. It perceives supervision as an academic position that requires work. Because supervisors should be active in research, appropriate development opportunities should be provided, and relevant institutional policies and procedures should be developed. This document provides little help in defining excellence in supervision.

Recently, a project funded by the Australian Bureau of Learning and Teaching at Edith Cowan University was implemented to develop a good practice framework for excellence in 
research training (Luca \& Wolski, 2013). It was supported by the Australian Council of Graduate Research. UK's Quality Assurance Agency (QAA) Code of Practice developed in 2004 provides institutions with a structural means to review and evaluate their research training practices helping identify gaps and areas of research training that can be developed or improved. The framework of QAA enables Australian institutions to align their research training processes with national good practice guidelines and to identify their strengths and opportunities for improvement. It deviates from defining excellence because instead of setting performance levels, it provides processes ... that enable universities to review the alignment of their goals, priorities, and practices with the Good Practice Framework.

Supervision prioritizes the public and practical policy without reference to the supervision practice. It highlights the institutional responsibilities related to ensuring that the supervisor's capacity is maintained as supervision is included in workload planning, and the quota is defined. There is a section on the eligibility of the supervision body, including experience, levels of research activity, qualifications, and continuous participation in supervision-related professional development. Supervisors should ensure that candidates are aware of the importance of and access to professional and career development opportunities. There is also a reference to the need to highlight the roles of members in the supervision team, the need for supervision mentoring programs for researchers in the early stages of their career, and the need for institutions to have a system for monitoring the performance of the supervisor and managing supervisors who are underperforming. The framework also states that progress reviews should enable effective processes to respond promptly when supervision is less than expected. Even though the framework mainly aims to operate at a developmental level rather than an organizational level, it does not provide any guidance on what to supervise or how organizations can identify "underperforming" or "below expectations" performance.

\section{Newzeland (McCulloch, Kumar, Van Schalkwyk, \& Wisker, 2016)}

At New Zealand universities, teaching is mostly defined by the standards of the National Center for Higher Teaching Excellence. As in Australia, these programs focus heavily on the "educational program". The National Level Award was created in 2001 to recognize and promote sustainable excellence in teaching in higher education institutions. Twelve sustainable excellence awards are presented annually: Ten for a general category and two for the Maori (Indigenous people of New Zealand). Furthermore, the Prime Minister's Prize is given to one recipient of the Sustainable Excellence Awards. These awards emphasize the idea of excellence that is introduced or maintained over an indefinite period, but there is little objective focus on the nature of excellence. For example, for the Maori category, excellence is demonstrated if the candidate can provide evidence of one of the following criteria: Focus on encouraging excellence, encouraging achievement in higher education, demonstrating commitment and openness to excellence. However, the term "sustainable excellence" within the general category remains vague because no expected standards, specifications, or competency criteria have been defined.

In the second example, excellence is indicated by asking the winners to write a brief essay for the "Excellence" handbook that provides an overview of the year's award winners. A review 
of these handbooks over the past five years shows that award recipients provided anecdotal accounts of their supervision experiences, suggesting that each experience is unique. Some supervisors mention the number of supervised students who graduated, completion on time, fellowship, and specific strategies. However, no special reference is made about the requirements of excellence in supervision.

\section{$>$ South Africa (McCulloch, Kumar, Van Schalkwyk, \& Wisker, 2016)}

The postgraduate landscape in South Africa is not good. In 2009, the review of the Higher Education Council showed that little progress was made in improving graduation rates despite many policy documents that encouraged improvement since the political change in 1994. For instance, the National Plan for Higher Education prioritized increasing the output of graduates, especially Ph.D. graduates, increasing search output, maintaining existing research capacity, establishing new excellence centers, facilitating partnerships of postgraduate research training, and enhancing interconnection between the different research components.

The review of the Centre for Research on Evaluation, Science and Technology (CREST) described the "accumulation" of students resulting from increased enrollment at master and doctoral levels without the increase in graduation rates. This has resulted in the "load of supervision" being increasingly placed on academics in South Africa whose numbers increased by $40 \%$ only in the same period. On average, a supervisor in 2005 had to supervise seven masters' and doctoral degree students at a high level in accordance with international standards. The age of supervisors is not considered.

Significant field variations exist with the supervision load in social sciences; about 12 students per supervisor. This fact relates to any discussion of excellence in the supervision of postgraduate studies. Many academics in South Africa prioritize finalizing their loads with notions of excellence.

In 2004, the Council of Higher Education set standards for institutional auditing that was to be conducted in all higher education institutions in South Africa. Two of these standards (15 and 17) were relevant to the postgraduate level but strongly focused on operational policy and strategic issues in relation to quality assurance, development, and control. There is no reference to the practice of supervision and is no evidence of the concept of excellence in supervision.

\section{United Kingdom (McCulloch, Kumar, Van Schalkwyk, \& Wisker, 2016)}

Since 2004, three official documents have been published about postgraduate research degrees. At first glance, these documents seem to provide more assistance because each document highlights a set of responsibilities that supervisors are expected to undertake. They were replaced by the UK Higher Education Quality Act, although subsequent documents underwent minor changes from the 2004 documents in terms of supervision. Three of the responsibilities were divided into separate points, with the sole responsibility, i.e., ensuring student awareness of the equal opportunity policy, being completely removed. The 2015 act states that: 
Supervision responsibilities may include:

$\checkmark$ Introducing the research student to the department (or equivalent), its facilities and procedures, and to other research students and relevant staff.

$\checkmark$ Providing satisfactory and accurate guidance and advice.

$\checkmark$ Monitoring the progress of the research student's research program.

$\checkmark \quad$ Establishing and maintaining regular contact with the research student (guided by the higher education provider's stated regulations and guidance).

$\checkmark$ Being accessible to the research student to give advice (by whatever means is most suitable, given the research student's location and mode of study).

$\checkmark$ Providing timely, constructive, and effective feedback on the research student's work and overall progress within the program.

$\checkmark$ Ensuring that the research student is aware of the need to exercise probity and conduct research according to ethical principles, including intellectual property rights, and of the implications of research misconduct.

$\checkmark$ Ensuring that the research student is aware of sources of advice, including careers guidance.

$\checkmark$ Helping research students understand health and safety responsibilities.

$\checkmark$ Helping the research student to interact with others working in the field of research, for example encouraging the research student to attend relevant conferences and supporting him/her in seeking funding for such events.

$\checkmark$ Giving encouragement and guidance to the research student on the submission of conference papers and articles to refereed journals.

Maintaining the necessary supervision expertise, including the appropriate skills, to perform all of the roles satisfactorily, supported by relevant continuing professional development opportunities.

The research relationship between the student and the supervisor is of paramount importance in all degrees of research. It requires providers of higher education to set systematic and clear supervision arrangements. Considering the supervision teams as the norm, the only indication of excellence relates to the supervisor's participation in the research, rather than supervision excellence itself. The relevant section states that "at least one, member of the student's supervision team is currently participating in an outstanding research in the relevant field(s), which ensures that directing and monitoring the student's progress is done by the supervisor who informs the researcher of the latest relevant knowledge and research". The document mentions industry involvement, supervisor's involvement with academic standards, Vitae researcher development framework (Vitae is the UK's main professional and career development body for higher education researchers), and postgraduate research experience questionnaire (higher education questionnaire for degree candidates). However, excellence is 
not defined beyond the expected competency.

$>$ Germany [The DRS Award for Excellent Supervision at Freie Universität Berlin (Carmesin, 2015)]

Since 2011, Dahlem Research School (DRS) at Freie Universität Berlin has honored exemplary commitment in doctoral supervision with the DRS Award for Excellent Supervision. The expectations for Good promotional supervision are manifold, including scientific support and psychological skills, assistance with career planning, and constant availability. In contrast to activities in research and teaching, lecturers' above-average commitment in this area is usually not sufficiently recognized and rewarded. Dahlem Research School wanted to change this with its DRS Award for Excellent Supervision. Two professors are rewarded with the prize annually and it is endowed with EUR 2,000 each. The prize money is intended for the advancement of young researchers.

Nomination based on a structured process: The selection of award winners is based on suggestions by doctoral candidates from DRS's current 27 doctoral programs. Nominating doctoral candidates must be in their final year so that they have experienced supervision in different phases and could assess it properly. A structured process and a specifically designed form have proven successful for nominations. In the first stage, doctoral candidates assess the intensity and quality of their supervision in different areas on a scale of 1-4. Predetermined criteria ensure that the entire scope of doctoral supervision is considered and that statements on the relationship between supervisor and supervisee are comparable.

The following fields are assessed:

$\checkmark$ Supervision of the doctoral dissertation: Setting a research timeline, regular consultations, and feedback, supporting the competition of the dissertation and preparation for the defense, and supporting the development of becoming an independent researcher.

$\checkmark$ Research Infrastructure: Access to the required equipment and resources, helping look for funding opportunities, developing more in-depth research methods, sharing good academic practice, and facilitating the development of an independent research mindset.

$\checkmark$ Integration into the national/international scientific community: Allowing the presentation of scientific results in seminars and conferences, introduction to the scientific community in and outside Germany, encouraging participation in international conferences, supporting the publication of research results, supporting the organization of a longer research stay abroad

$\checkmark$ Career counseling: Jointly providing career counseling both in and outside academia, supporting the acquisition of transferrable skills, and advising on seeking funding as a postdoctoral researcher.

The second stage concerns the individual priorities within the relationship between supervisor and doctoral candidate. Supervisees are asked to justify their nomination by freely describing the relationship and offering more detailed or additional information that they deem 
important. The resulting texts are often impressive descriptions of exceptional commitment. Both parts of the nomination are weighted equally in the selection of winners.

$\checkmark$ Anonymized selection: The further selection process is confidential and objective. Once submitted to DRS, the nominations are anonymized. All references to the name, gender, and the doctoral program are censored so that the selection committee- which is made up of doctoral candidates and DRS employees- can come to no conclusions regarding the submitting candidate or the nominated supervisor. Furthermore, a major concern of doctoral candidates has been taken very seriously: Winners are never informed about the identity of the doctoral candidate who nominated them. Moreover, during the award ceremony, speakers will only quote passages of the nominations with the submitting doctoral candidate's agreement.

$\checkmark \quad$ Public appreciation: The award is presented at the annual ceremony on the founding day of Freie Universität. Two reasons make it the ideal forum: Firstly, it provides an adequate setting to celebrate the award. The winners are honored with a laudation that quotes excerpts from the nominations, and then receive a certificate in front of about 200 attendees, including alumni of Freie Universität, doctoral candidates, employees, and colleagues of the laureates. Secondly, this is the traditional day on which the best dissertations of the past year are honored. Increasingly, this combination of publicly honoring doctoral candidates and supervisors in making the day a celebration of young researchers and the promotion of young talent.

$\checkmark$ A contribution to the debate on doctoral supervision: In only three years, the DRS Award for Excellent Supervision has become a tradition at Freie Universtität Berlin. The growing number of nominations and exclusively positive reactions confirm that it is beneficial and important to steer the attention of the university itself, as well as the public, to the excellent work that is done in this core area of promoting young researchers daily and which tends to go almost unnoticed. By providing positive examples, the award can help promote the exchange of individual supervision practices, but also establish university-wide guidelines for doctoral supervision.

\section{Literature Review}

Roberts, Gentry, and Townsend (2011) evaluated the administration of a doctoral program in higher education to understand students' perceptions of the quality of the program to improve both student satisfaction and future planning. The study used the descriptive approach and the interview as a tool for data collection. The study showed that the care, support, teaching, and application of the curriculum content are excellent and useful. It also highlighted some challenges facing the administration of the doctoral program, including the lack of continuity of leaders due to the administrative rotation in the department, the constant change of policies and practices, the lack of support and advice for students, and the lack of preparing good research for doctoral dissertations.

Al-Tokhi (2011) made a proposal of the professional development of faculty members at Egyptian universities in research supervision in the light of identifying their professional 
needs and benefiting from foreign experiences. The author conducted a field study and applied a questionnaire to a sample of faculty members at Cairo University. Ali (2015) proposed a vision for the development of academic supervision at the faculties of education in Egyptian universities and in the light of the results of the reality analysis and exploration of prospects. The study handled the following items: The concept, characteristics, and patterns of academic supervision, as well as its most important elements (supervisor, student, research topic, and research environment). Then, it presented the most important global experiences in the field, especially those of the universities of Manchester in Britain, British Columbia in Canada, and South Australia in Australia), and identified ways to benefit from these models. After that, it addressed the reality of academic supervision at the faculties of education in Egyptian universities and made recommendations for development.

El-Deeb (2016) examined and made a plan to resolve the problems of academic supervision of postgraduate studies (theses and dissertations) at the Kindergarten Department, Faculty of Education, Tanta University. The study adopted the analytical descriptive method and case study and applied a questionnaire to (50) researchers from 2010 to 2016. The results highlighted many pre-enrollment problems, such as defined two times of enrollment (September- April), wasting time in enrollment, and hastness of choosing the topic. Enrollment problems include lack of supervisor flexibility, whereas post-enrollment problems include a heavy load of supervisors.

Assakran (2016) explored the reality and obstacles of academic supervision in departments of education at Al-Imam Muhammad Ibn Saud Islamic University and identified a vision of the role of supervisor. The author used the analytical descriptive method and applied the tool to all postgraduate students numbered (199). The results showed that the role of the supervisor was weak in the administrative and academic aspects and moderate in the human aspect. Some obstacles hinder this role, e.g., heavy load, lack of experience, and lack of commitment to office hours. Thus, the study concluded a vision of developing the role of the academic supervisor, including the objectives of supervision, duties of the supervisor, duties of the students, and mechanisms of achieving the objectives.

Jan (2017) examined the reality of academic supervision of postgraduate educational research at Umm Al-Qura University by identifying the human, cognitive, and administrative aspects of the supervisor. The author employed the descriptive approach and applied a close questionnaire. The study recommended that supervisors should reconsider the human aspect of supervision.

Awn, Saab, and Alqahtany (2019) identified the reality and criteria of evaluating postgraduate studies programs at the Department of Educational Administration, College of Education, King Saud University from the student perspective (concerning courses) and the requirements of development in the light of Saudi Vision 2030. The authors adopted the descriptive survey approach and applied a questionnaire to (44) students. The results showed that the department offers a suitable teaching environment, and the content of courses helps develop research, exploration, and discovery among students.

Johansen et al. (2019) explored team supervision and examined the relationship between the 
principal and co-supervisors concerning integrity in the distribution of rules and responsibilities of supervision teams. They adopted a descriptive qualitative approach and objective analysis to analyze deep interviews with (10) supervisors distributed to (5) Ph.D. supervision teams. The results showed that the participants understand their responsibilities. They agreed that the major responsibility is that of the principal supervisor. However, no conflict of responsibility was reported.

Löfström and Pyhältö (2020) explored the ethics of Ph.D. supervision and how they matter. The authors collected data from (26) Ph.D. students at two research universities in Finland with international reputation and important national and regional roles. The results illustrated that ethics affect the positive and negative results of Ph.D., including satisfaction with study and supervision. The five ethics were divided into three domains: (1) research community and supervision structure (shape), (2) justice and integrity (rules), and (3) respect-based relationships (care).

Ribau (2020) highlighted Ph.D. practices at NOVA University Lisbon from the perspective of students and supervisors. Two three-month surveys were conducted. The students had to choose (agree, partially agree, partially disagree, or disagree with positive and negative items) and answer an optional open question about the characteristics of a good supervisor and the supervision practices. The supervisors had to choose (agree, partially agree, partially disagree, or disagree with positive and negative items) and answer two optional open questions about the reasons for being a supervisor and the personal meaning of obtaining a Ph.D. degree. The results showed that (individual or group) meetings are the most common practice. Furthermore, good supervisors are honest and interested in students and give feedback about their work.

\section{Methodology and Procedures}

The general framework of the study covers the conceptual framework and achieving the objectives. It also includes the field study, its objectives, sampling, population, and tools.

\subsection{Sampling and Population}

The population covered the faculty members at the Faculty of Education, Damietta University numbered (117). The sample comprised the supervisors of postgraduate studies at the Faculty of Education, Damietta University numbered (30) from different departments. The participants were interviewed. Table (1) shows the number of students of the master and Ph.D. degrees at the Faculty of Education, Damietta University. 
Table 1. The number of students enrolled for the master's and Ph.D. degrees at the Faculty of Education

\begin{tabular}{|l|l|l|l|}
\hline No. & Department & Master's students & Ph.D. students \\
\hline 1 & Special Education & 115 & 9 \\
\hline 2 & Educational Psychology & 14 & 11 \\
\hline 3 & Mental Health & 118 & 26 \\
\hline 4 & Foundations of Education & 218 & 61 \\
\hline 5 & Educational Technology & 66 & 31 \\
\hline 6 & Curriculum \& Instruction & 202 & 84 \\
\hline Total & & 733 & 222 \\
\hline
\end{tabular}

Tables 2 and 3 show the number of on-job faculty members and assistants at the Faculty of Education.

Table 2. Number of on-job faculty members and assistants at the Faculty of Education (distributed to the departments)

\begin{tabular}{|c|c|c|c|c|c|c|c|c|c|c|c|c|c|c|c|c|c|c|c|c|}
\hline Department & \multicolumn{2}{|c|}{ 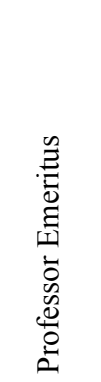 } & \multicolumn{2}{|c|}{ 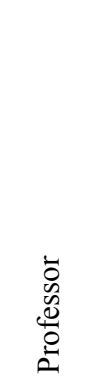 } & \multicolumn{2}{|c|}{ 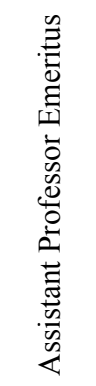 } & \multicolumn{2}{|c|}{ 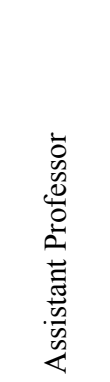 } & \multicolumn{2}{|c|}{ 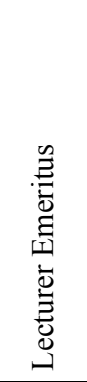 } & \multicolumn{2}{|c|}{ 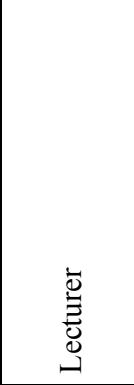 } & \multicolumn{2}{|c|}{ 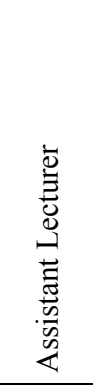 } & \multicolumn{2}{|c|}{ 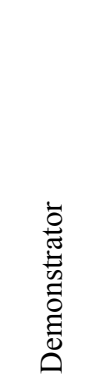 } & \multicolumn{2}{|c|}{ 吾 } & 要 & 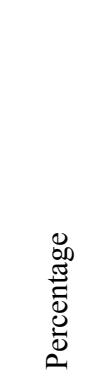 \\
\hline $\begin{array}{l}\text { Curriculum \& } \\
\text { Instruction }\end{array}$ & 9 & 2 & 1 & 1 & & & 2 & 2 & 1 & 1 & 2 & 10 & 1 & 5 & & 3 & 16 & 24 & 40 & $34.19 \%$ \\
\hline $\begin{array}{l}\text { Educational } \\
\text { Technology }\end{array}$ & & & 2 & 1 & & & 3 & 3 & & & 3 & 1 & & & 3 & 8 & 11 & 13 & 24 & $20.51 \%$ \\
\hline $\begin{array}{l}\text { Foundations } \\
\text { of Education }\end{array}$ & 2 & 3 & 1 & & & 1 & 2 & 3 & 1 & & 1 & 2 & & & 1 & 2 & 8 & 11 & 19 & $16.24 \%$ \\
\hline Psychology & & 1 & 2 & 1 & 6 & & & 1 & & & 2 & 5 & & 2 & & 4 & 10 & 14 & 24 & $20.51 \%$ \\
\hline Kindergarten & & & & & & & & 2 & & & 2 & 4 & & & & 2 & 2 & 8 & 10 & $8.55 \%$ \\
\hline Total & 11 & 6 & 6 & 3 & 6 & 1 & 7 & 11 & 2 & 1 & 10 & 22 & 1 & 7 & 4 & 19 & 47 & 70 & 117 & \\
\hline
\end{tabular}




\section{Macrothink}

Table 3. Number of on-job faculty members and assistants at the Faculty of Education

\begin{tabular}{|c|c|c|c|c|c|c|c|c|c|c|c|c|c|c|c|c|c|c|c|c|}
\hline Faculty & 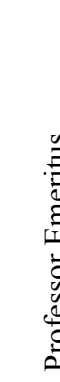 & & s & & 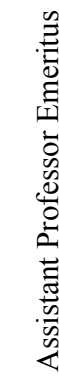 & & & 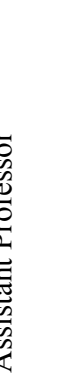 & . & & & & 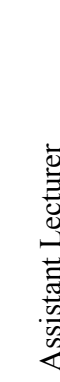 & & & 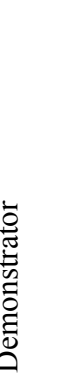 & 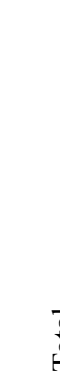 & & 馬 & 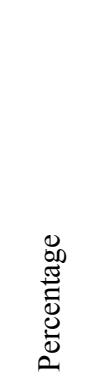 \\
\hline Faculty of Education & 11 & 6 & 6 & 3 & 6 & 1 & 7 & 11 & 2 & 1 & 10 & 22 & 1 & 7 & 4 & 19 & 47 & 70 & 117 & $100 \%$ \\
\hline Total & 11 & 6 & 6 & 3 & 6 & 1 & 7 & 11 & 2 & 1 & 10 & 22 & 1 & 7 & 4 & 19 & 47 & 70 & 117 & \\
\hline
\end{tabular}

\subsection{Tools}

The study adopted the interview to collect data because it relies on direct interaction and truthfulness and gives the best results. The tool consists of two domains, as follows:

\subsubsection{Domain I: Answer to the First Question}

The most significant obstacles to the supervisor of postgraduate studies at the Faculty of Education, Damietta University cover 14 items, as shown in Table 4. 


\section{MInstitute Macrothink $_{\text {Int }}$}

Table 4. The most significant obstacles to the supervisor of postgraduate studies at the Faculty of Education, Damietta University

\begin{tabular}{|c|c|c|c|c|}
\hline No. & Items & Agree & Undecided & Disagree \\
\hline 1 & The heavy load of the supervisor & & & \\
\hline 2 & $\begin{array}{l}\text { The department obliges the academic supervisor } \\
\text { to supervise students to complete the quota. }\end{array}$ & & & \\
\hline 3 & A large number of supervised students & & & \\
\hline 4 & Lack of regulations of supervision assessment & & & \\
\hline 5 & Unclear internal regulations related to supervisors' tasks & & & \\
\hline 6 & Student tendency to choose a supervisor of a certain capacity. & & & \\
\hline 7 & $\begin{array}{l}\text { Researcher's tendency to carry out the study } \\
\text { as fast as possible regardless of quality }\end{array}$ & & & \\
\hline 8 & Poor scientific research skills among postgraduate students & & & \\
\hline 9 & Supervisors' occupancy with teaching load & & & \\
\hline 10 & Student interest in the academic degree regardless of level or quality & & & \\
\hline 11 & Delay of conducting studies and seeking expansion & & & \\
\hline 12 & Lack of commitment to paying the entitlement of the supervisor & & & \\
\hline 13 & Lack of the students' interaction with the supervisor & & & \\
\hline 14 & Disregard of the major in supervision & & & \\
\hline
\end{tabular}

\subsubsection{Domain II: Answer to the Second Question}

The author interviewed the selected sample of (30) faculty members who supervise educational postgraduate studies.

\section{Results and Discussion}

4.1 Domain I: The Most Significant Challenges to the Academic Supervision of Postgraduate Studies at the Faculty of Education, Damietta University

The domain aims to identify the agreement of the participants on the most significant challenges to the academic supervision of educational postgraduate studies. The author collected the responses and defined the arithmetic means of agreement. The results showed that $90 \%$ of the participants agreed on the following challenges: Heavy load of the supervisor, student tendency to choose a supervisor of a certain capacity, student keenness to carry out the study as fast as possible regardless of quality, poor scientific research skills among 
postgraduate students, supervisor occupancy with teaching loads and considering the major in supervising, and lack of commitment of the university to pay the entitlements of the supervisor.

The results agree with the literature, such as Robert, Gentry, and Townsend (2011) that reported some challenges, including the continuous change of policies and practices, lack of student support, duplicated curricula, and poor research for dissertations. El-Deeb (2016) concluded that some supervisors are inflexible and oblige students to explore certain topics according to their major and experience. Moreover, Assakran (2016) highlighted several challenges, such as heavy load, lack of academic experience, and lack of commitment to the office hours of the supervisors.

Most of the participants disagreed on some challenges, e.g., lack of regulations of supervision assessment, unclear internal regulations related to supervisor's tasks, occupancy with teaching load, and delay of achieving studies and seeking a longer period of study.

\subsection{Results of the Question on the Most Significant Challenges From the Perspective of the Participants}

The participants reported several challenges, e.g., establishing the regulations of academic supervision. They showed that a code of conduct about the rights and duties of the researcher and student should be established. They agreed that the students should be followed continually, and the role of the seminar should be activated in following-up students. Furthermore, the major of the supervisor should be considered in supervising theses and dissertations, and accurate criteria for choosing postgraduate students should be set. The teaching load of the supervisor should be reduced, and increasing the incentives of supervision and examination should be activated. The participants also reported the need to set regular dates for meeting the students and resolving the problems related to theses and dissertations. Concerning the student, one should approve the committees of supervision and examination and should be awarded very well in the first university degree. Additionally, the quota of supervision should not exceed ten researchers. Strict regulations should be established, and no time expansion is approved.

\section{Recommendations}

The study recommends several mechanisms of improving the quality of academic supervision, such as:

$\checkmark$ The teaching load of the supervisor should be reduced for the sake of conducting studies supervising theses and dissertations.

$\checkmark$ Certain dates of supervision should be defined in academic schedules.

$\checkmark$ Databases of theses and dissertations should be created and provided to researchers and supervisors.

Modern means of communication should be employed in supervision.

$\checkmark$ A periodic report of the student achievement should be presented. 


\section{Macrothink}

$\checkmark$ Regulations of academic supervision should be established.

$\checkmark \quad$ A code of conduct about the rights and duties of the researcher and student should be established.

$\checkmark$ The major of the supervisor should be considered in supervising theses and dissertations.

$\checkmark$ The financial entitlements of supervisors should be paid, and the incentive of supervision and examination should be raised.

$\checkmark$ Accurate criteria for choosing postgraduate students should be set.

$\checkmark$ Students should be followed continually, and the role of the seminar should be activated in following-up students.

$\checkmark$ Regular times of following-up and meeting students should be set to resolve relevant problems.

$\checkmark$ The researcher's approval of supervision and examination committees should be considered.

$\checkmark$ A researcher of the master's and Ph.D. degrees should be awarded very well at least in the first university degree.

$\checkmark$ Defining the quota of supervision to ten researchers.

\section{Conclusion}

Academic supervision is a comprehensive process among researchers, supervisors, and examiners. It suffers many challenges to dissertations and theses and obstacles to supervisors. Thus, the present study aimed to identify and resolve these challenges. It reviewed literature and the most important international models of academic supervision to establish accurate criteria to resolve such challenges, e.g., choosing postgraduate students accurately, following up students continually, activating the role of the seminar in following up students, considering the approval of the researcher of supervision and examination committees, as well as setting rules of supervision practices. To resolve the challenges to academic supervision, supervisors, researchers, and parties interested in scientific research at university should collaborate to improve the quality of academic supervision and improve the results of research, dissertations, and theses at the colleges of education to develop the educational system in general.

\section{References}

Abu Daf, M. (2002). Evaluating the role of the university professor in supervising theses from the postgraduate student perspective. Journal of Reading and Knowledge, 17, 15-45.

Abulsaoud, S. (2020). Obstacles to educational research and resolving them in Egypt. Educational and Psychological Studies, 106(1), 279-316.

Ali, M. (2015). Developing academic supervision at the colleges of education, Egyptian 
universities based on some global expertise (Master's thesis, Cairo University, Egypt).

Ali, A., \& Merghany, A. (2011). The role of researchers'skills and supervisors' experience in preparing theses and dissertations. A paper presented to the First Scientific Symposium of Developing Theses and Dissertations and Activating their Role in Comprehensive and Sustainable Development, Naif Arab University for Security Sciences, Saudi Arabia.

Alloma, H. (2019). Problems of scientific research facing postgraduate students at the Faculty of Educational Sciences, AL-Hussein Bin Talal University from their perspective. AL-Hussein Bin Talal University Journal, 5(2), 46-64.

Alnaqa, M. (2005). Experience of Egyptian universities in preparing and developing university lecturer. A paper presented to the $12^{\text {th }}$ Annual National Conference "Developing the Performance of Arab Universities in the Light of Total Quality and Accreditation Systems", Ain Shams University, Egypt.

Al-Sawi, M. (2006). Educational research ethics: Inputs and outputs. A paper presented to the Fourth Annual Scientific Conference "Developing Programs for Colleges of Education in the Arab World in the Light of Local and International Developments", Zagazig University, Egypt.

Al-Tokhi, H. (2011). Professional development of faculty members in research supervision: A proposal. Journal of Education Science, 19(4), 149-180.

Assaf, M. (2014). Academic supervision at Palestinian Universities: A field study. Kuwait Educational Journal, 28(111), 3555-406.

Assakran, A. (2016). The developmental vision of the role of the academic supervisor of theses, dissertations, and complementary research of postgraduate students in departments of education at Al-Imam Muhammad Ibn Saud Islamic University. Journal of Education Sciences, 6(1), 15-76. https://doi.org/10.12816/0030297

Awn, W., Saab, M., \& Alqahtany, A. (2019). Evaluating postgraduate studies programs at the Department of Educational Administration, College of Education, King Saud University in the light of Saudi Vision 2030. Journal of Assiut Faculty of Education, 35(7), 30-62.

Calma, A. (2008). Postgraduate supervision in the Philippines: Setting the research agenda. The Asia-Pacific Education Researcher, 16(1), 91-100. https://doi.org/10.3860/taper.v16i1.94

Carmesin, B. (2015). Doctoral supervision recommendations and good practice for universities and doctoral supervisors. UniWiND Publications, 4, 1-34

Diab, S. (2009). An evaluation study of the role of the academic supervisor in supervising and following-up student graduation projects at Al-Quds Open University. Palestinian Journal of Open Education, 2(3), 99-126.

Down, C., Martin, E., \& Bricknell, L. (2000). Student-focused postgraduate supervision: A mentoring approach to supervising postgraduate students. Melbourne: RMIT University.

El-Deeb, R. (2016). Academic supervision of studies between reality and expectations: A case 
study of Kindergarten Department, Faculty of Education, Tanta University. Journal of Childhood and Development, 27(8), 87-156.

Falia, F., \& Alzaky, A. (2004). Dictionary of education. Alexandria, Egypt: Alwafaa Press.

Freie Universität Berlin. (2011). DRS Supervision Award. Retrieved from https://www. fu-berlin.de/sites/drs/about-us/excellent_supervision/index.html

Hassan, A. (2010). Expectations of the role in academic supervision. Journal of Educational Science, 18(1), 3-58.

Ibrahim, A. (2017). Developing educational postgraduate studies at the Egyptian universities as thinking incubators based on knowledge economy requirements: A proposal. Journal of Scientific Research in Education, 8(18), 193-218.

Jan, K. (2017). Reality of academic supervision of postgraduate educational research at Umm Al-Qura University from the researcher's perspective. Al-Azhar Journal of Education, 2(175), 262-302.

Johansen, B., Olsen, R., Øverby, N., Garred, R., \& Enoksen, E. (2019). Team supervision of doctoral students: A qualitative inquiry. International Journal of Doctoral Studies, 4, 69-84. https://doi.org/10.28945/4177

Löfström, E., \& Pyhältö, K. (2020). What are ethics in doctoral supervision, and how do they matter? Doctoral students' perspective. Scandinavian Journal of Educational Research, 64(4), 535-550. https://doi.org/10.1080/00313831.2019.1595711

Luca, J., \& Wolski, T. (2013). Higher degree research training excellence: A good practice framework. Retrieved from https://ltr.edu.au/resources/SI11_2102_Luca_Report_2013.pdf

Madkour, A. (2000). Higher education in the Arab World: Way to the future. Cairo, Egypt: Dar Alfikr Alaraby.

Marzuq, F. (2017). Educational research and its relationship to sustainable development: A case study of Cairo University. Journal of Education Science, 25(3), 48-149.

McCulloch, A., Kumar, V., Van Schalkwyk, S., \& Wisker, G. (2016). Excellence in doctoral supervision: An examination of authoritative sources across four countries in search of performance higher than competence. Quality in Higher Education, 22(1), 64-77. https://doi.org/10.1080/13538322.2016.1144904

Mustafa, J. (2004). An evaluative study of the academic supervisor's role at the colleges of education based on the necessary competencies (Ph.D. dissertation, Al-Azhar University, Egypt).

Noureddine, T. (2009). University academic supervision: Concept, elements, and obstacles. Journal of Dar El-Ulum for Arabic Language, Literature, and Islamic Studies, 16(33), 277-296.

Ribau, I. (2020). Doctoral supervisors and Ph.D. students' perceptions about the supervision 


\section{Macrothink}

Journal of Educational Issues

ISSN 2377-2263

2021, Vol. 7, No. 1

process in a young European university. Universal Journal of Educational Research, 8(1), 36-46. https://doi.org/10.13189/ujer.2020.080105

Roberts, J., Gentry, D., \& Townsend, A. (2011). Student perspectives: Evaluating a higher education administration program. Journal of Case Studies in Education, 1, 1-20.

Shaban, A. (2017). Scientific supervision in the educational departments at Cairo University: Exploring the students' views of the Faculty of Postgraduate Studies in Education. The Future of Arab Education, 24(108), 11-84.

\section{Copyright Disclaimer}

Copyright for this article is retained by the author(s), with first publication rights granted to the journal.

This is an open-access article distributed under the terms and conditions of the Creative Commons Attribution license (http://creativecommons.org/licenses/by/3.0/). 